Article

\title{
GC-MS Screening Analysis for the Identification of Potential Migrants in Plastic and Paper-Based Candy Wrappers
}

\author{
Soraya Galmán Graíño, Raquel Sendón ${ }^{(D)}$, Julia López Hernández ${ }^{(D)}$ and \\ Ana Rodríguez-Bernaldo de Quirós * (D) \\ Department of Analytical Chemistry, Nutrition and Food Science, Faculty of Pharmacy, \\ University of Santiago de Compostela, 15782-Santiago de Compostela, Spain; \\ galman.graino@gmail.com (S.G.G.); raquel.sendon@usc.es (R.S.); julia.lopez.hernandez@usc.es (J.L.H.) \\ * Correspondence: ana.rodriguez.bernaldo@usc.es; Tel.: +34-881-81-4965
}

Received: 15 June 2018; Accepted: 18 July 2018; Published: 21 July 2018

\begin{abstract}
Food packaging materials may be a potential source of contamination through the migration of components from the material into foodstuffs. Potential migrants can be known substances such as additives (e.g., plasticizers, stabilizers, antioxidants, etc.), monomers, and so on. However, they can also be unknown substances, which could be non-intentionally added substances (NIAS). In the present study, non-targeted analysis using mass spectrometry coupled to gas chromatography (GC-MS) for the identification of migrants in plastic and paper-based candy wrappers was performed. Samples were analyzed after extraction with acetonitrile. Numerous compounds including $N$-alkanes, phthalates, acetyl tributyl citrate, tributyl aconitate, bis(2-ethylhexyl) adipate, butylated hydroxytoluene, etc. were identified. Many of the compounds detected in plastic samples are not included in the positive list of the authorized substances. One non-intentionally added substance, 7,9-Di-tert-butyl-1-oxaspiro(4,5)deca-6-9-diene-2,8-dione, which has been reported as a degradation product of the antioxidant Irganox 1010, was found in several samples of both plastic and paper packaging. The proposed method was shown to be a useful approach for the identification of potential migrants in packaging samples. The toxicity of the compounds identified was estimated according to Cramer rules. Then, a second targeted analysis was also conducted in order to identify photoinitiators; among the analyzed compounds, only 2-hydroxybenzophenone was found in five samples.
\end{abstract}

Keywords: GC-MS; non-targeted analysis; targeted analysis; photoinitiators; NIAS; candy wrappers

\section{Introduction}

Packaging has become essential since protecting packaged food from contamination facilitates their transport and increases their shelf life. However, the use of packaging introduces a safety concern because of the possible migration of dangerous substances from the packaging material into the foodstuffs [1-3]. Additives, components of the printing inks such as photoinitiators or residues of monomers are some of the substances of special interest from the food safety point of view. The additives such as plasticizers, slip agents, antioxidants, stabilizers, UV absorbers, etc. are used to improve the properties of the materials.

These substances of low molecular weight are of major concern, since they would be absorbed in the digestive tract, and could represent a risk to the health of the consumer. On the other hand, they can also produce changes in the organoleptic properties of the food.

Besides intentionally added substances, non-intentionally added substances (NIAS) including impurities of additives and monomers, degradation or reaction products, and neo-formed compounds may remain in the final product and consequently reach the packaged food $[4,5]$. 
All food contact materials and articles are regulated by the Framework Regulation (EC) No 1935/2004 [6]. The aforementioned regulation lays down the requirements that must be fulfilled by materials and articles that are intended to come into contact with food. In summary, under foreseeable conditions of use, they must not release components in quantities that represent a danger to human health, cause an unacceptable change in the composition of the food, or cause alterations in the organoleptic characteristics. In addition, labeling and advertising must not mislead consumers.

For plastic food contact materials, Regulation (EU) 10/2011 [7] includes the European Union positive list of monomers, additives, and starting substances allowed in the manufacture of plastic food contact materials and the restrictions of use, namely the specific migration limit (SML), overall migration, and limit of content of the substance in the material or article. This regulation also mentions the need to consider NIAS for risk assessments. Paper and cardboard are also widely used for food packaging applications, but the regulation for these materials is not harmonized at the community level.

The identification of potential migrants is the first step to evaluate the safety of food packaging materials. Mass spectrometry coupled to gas chromatography (GC-MS) for volatile and semi-volatile compounds or liquid chromatography (LC-MS) for non-volatile compounds appears as a useful and powerful technology for targeted and untargeted analysis.

In this work, a GC-MS non-targeted analysis for the identification of unknown potential migrants both intentionally and non-intentionally added substances in plastic and paper-based candy wrappers was carried out. A targeted analysis to identify specifically certain photoinitiators was also performed. The toxicity of the identified compounds was estimated by means of Cramer rules. The analysis of this type of packaging is of particular interest since the main consumers of sweets are children, who are a vulnerable group from the exposure point of view. Furthermore, the relationship food/food contact material is bigger than in other food products, which favors the migration.

\section{Materials and Methods}

\subsection{Reagents and Standards}

Methanol, acetonitrile, n-hexane, and tetrahydrofuran liquid chromatography grade were provided from Merck KGaA (Darmstadt, Germany). Ultrapure water (Type I) was obtained with an Automatic Plus purification system (Wasserlab, Navarra, Spain). All of the analytical standards were from Sigma Aldrich (St. Louis, MO, USA). Acetyl tributyl citrate ( $\geq 98 \%$ ) (CAS 77-90-7); benzyl butyl phthalate ( $\geq 98 \%$ ) (CAS 85-68-7); butylated hydroxytoluene ( $\geq 99 \%$ ) (CAS 128-37-0); bis(2-ethylhexyl) adipate ( $\geq 99 \%$ ) (CAS 103-23-1); bis(2-ethylhexyl) phthalate ( $\geq 98 \%$ ) (CAS 117-81-7); diethyl phthalate $(\geq 99 \%)$ (CAS 84-66-2); diisobutyl phthalate ( $\geq 99 \%$ ) (CAS 84-69-5); squalene ( $\geq 98 \%$ ) (CAS 111-02-4); octadecane ( $\geq 99.9 \%$ ) (CAS 593-45-3); triacetin ( $\geq 99 \%$ ) (CAS 1029-76-1); glycerol tricaprylate $(\geq 99 \%)$ (CAS 538-23-8). C7-C30 Saturated alkane mixture (1000 $\mu \mathrm{g} / \mathrm{mL}$ each component in hexane).

Photoinitiators standards: 1-hydroxycyclohexyl-phenyl-ketone (99\%) (CAS 947-19-3); 2,2-dimethoxy2-phenyl acetophenone (99\%) (CAS 24650-42-8); methyl-2-benzoylbenzoate (97\%) (CAS 606-28-0); 2-hydroxybenzophenone (99\%) (CAS 117-99-7); 4-methyl benzophenone (99\%) (CAS 134-84-9); 4-phenyl benzophenone (99\%) (CAS 2128-93-0); ethyl-4-(dimethylamino)benzoate (99\%) (CAS 10287-53-3) were obtained from Aldrich (St. Louis, MO, USA) and benzophenone (99\%) (CAS 119-61-9) was from Fluka (Stenheim, Switzerland).

Stock standard solutions were prepared in acetonitrile and hexane and stored at $4{ }^{\circ} \mathrm{C}$ until the analysis.

\subsection{Samples and Extraction Procedure}

Several candy wrappers based on plastic and paper materials and from different brands and two popcorn packages were analyzed in order to identify potential migrants. Table 1 summarized the samples analyzed in the study. 
Table 1. Samples analyzed in the study.

\begin{tabular}{cccc}
\hline & Plastic Based Materials & & Paper Based Materials \\
\hline Code & Sample description & Code & Sample description \\
\hline P1 & Strawberry candy brand 0 & M1.1 & Banana chewy candy brand A \\
P2 & Strawberry lollipop brand 1 & M1.2 & Strawberry chewy candy brand A \\
P3.1 & Cherry chewy candy brand 2 & M2.1 & Coke chewy candy brand B \\
P3.2 & Strawberry chewy candy brand 2 & M2.2 & Lemon chewy candy brand B \\
P4 & Strawberry lollipop brand 3 & M.3 & Strawberry chewy candy brand C \\
P5 & Lemon candy brand 4 & M.4 & Blackberry candy brand D \\
P6 & Lemon candy brand 5 & M.5 & Bilberry candy brand D \\
P7 & Strawberry chewy candy brand 6 & PA1 & Popcorn brand E \\
& & PA2 & Popcorn brand F \\
\hline
\end{tabular}

To extract the migrants, a known surface of the packaging material was put in contact with $25 \mathrm{~mL}$ of acetonitrile for $6 \mathrm{~h}$ at $70{ }^{\circ} \mathrm{C}$. Then, the extracts were evaporated in a rotavapor system (Buchi, Postfach, Switzerland), and the residue was re-dissolved in a known volume of acetonitrile. An aliquot of the resulting solution was filtered through a $0.45 \mu \mathrm{m}$ filter (Advanted, Toyo Roshi Kaisha, Ogawa-machi, Hiki-gun, Saitama, Japan) and injected into the GC-MS.

\subsection{Equipment}

\section{GC-MS Analysis}

\section{Non-Targeted Analysis}

A Thermo Scientific Trace 1300 Series gas chromatograph (Thermo Fisher Scientific, San José, CA, USA) with a Trace ISQ LT mass detector (San José, CA, USA) (GC-MS) equipped with a Thermo Scientific AI 1310 automatic injector (San José, CA, USA) was used to carry out the analysis. The chromatographic conditions were as follows: a ZB-5MS $(30 \mathrm{~m} \times 0.25 \mathrm{~mm} \times 0.25 \mu \mathrm{m})$ column from Phenomenex ${ }^{\circledR}$ (Torrance, CA, USA) was employed; the injector temperature was $300{ }^{\circ} \mathrm{C}$. The injection mode was splitless, and the injection volume $1 \mu \mathrm{L}$. Helium was the carrier gas at a flow of $1 \mathrm{~mL} / \mathrm{min}$. The transfer line and source temperature were set at $300^{\circ} \mathrm{C}$. The oven temperature was initially at $40{ }^{\circ} \mathrm{C}$ for $2 \mathrm{~min}$, then increased at a rate of $9{ }^{\circ} \mathrm{C} / \mathrm{min}$ until $300{ }^{\circ} \mathrm{C}$ and held at $300{ }^{\circ} \mathrm{C}$ for $3 \mathrm{~min}$. The chromatograms were acquired in full scan mode $(\mathrm{m} / \mathrm{z} 35-500)$. The mass spectral libraries NIST/EPA/NIH 11 (version 2.0) and Wiley Registry TM 8th edition were used for identification purposes.

Targeted Analysis

Under the same chromatographic conditions, a targeted analysis to identify the photoinitiators in the extracts of the packaging samples was performed. The analyses were conducted using SIM mode.

\section{Results and Discussion}

\subsection{Non-Targeted Analysis}

\subsubsection{Plastic-Based Materials}

A total of eight plastic candy wrappers were analyzed in order to identify potential migrants; for that purpose, a GC-MS non-targeted screening was carried out.

Firstly, packaging samples were extracted, several extraction solvents and time-temperature conditions were tried (acetonitrile $6 \mathrm{~h}: 70^{\circ} \mathrm{C}$; acetonitrile $24 \mathrm{~h}: 70^{\circ} \mathrm{C}$; hexane $4 \mathrm{~h}: 60^{\circ} \mathrm{C}$; tetrahydrofuran $4 \mathrm{~h}: 60{ }^{\circ} \mathrm{C}$ and methanol $24 \mathrm{~h}: 70{ }^{\circ} \mathrm{C}$ ) with the aim to achieve the most suitable extraction for the most compounds. It was observed that hexane extracted less analytes than the other solvents tested. 
Particularly, the compounds eluted in the first $20 \mathrm{~min}$. On the other hand, THF and methanol showed a lower extraction efficiency compared with acetonitrile (ACN). When ACN was used as an extraction solvent, no important differences were observed regarding the extraction time. The best conditions turned out to be acetonitrile as extraction solvent at $70{ }^{\circ} \mathrm{C}$ for $6 \mathrm{~h}$.

Twenty three volatile and semi-volatile compounds were identified. Eighteen compounds were positively confirmed by comparison with standards and the rest of the compounds were tentatively identified.

Cramer rules were applied in order to estimate the toxicity of the compounds identified. The software used was Toxtree v2.6.13 (Ideaconsult Ltd., Sofia, Bulgaria) (based on a decision tree approach) [8]. Substances are classified into three classes taking into account their chemical structures; thus, class I corresponds to low toxicity, and class II and class III correspond to intermediate and high toxicity, respectively [9].

Chromatograms corresponding to samples M1.1, M3, P4, and P3.1 are presented in Figure 1.

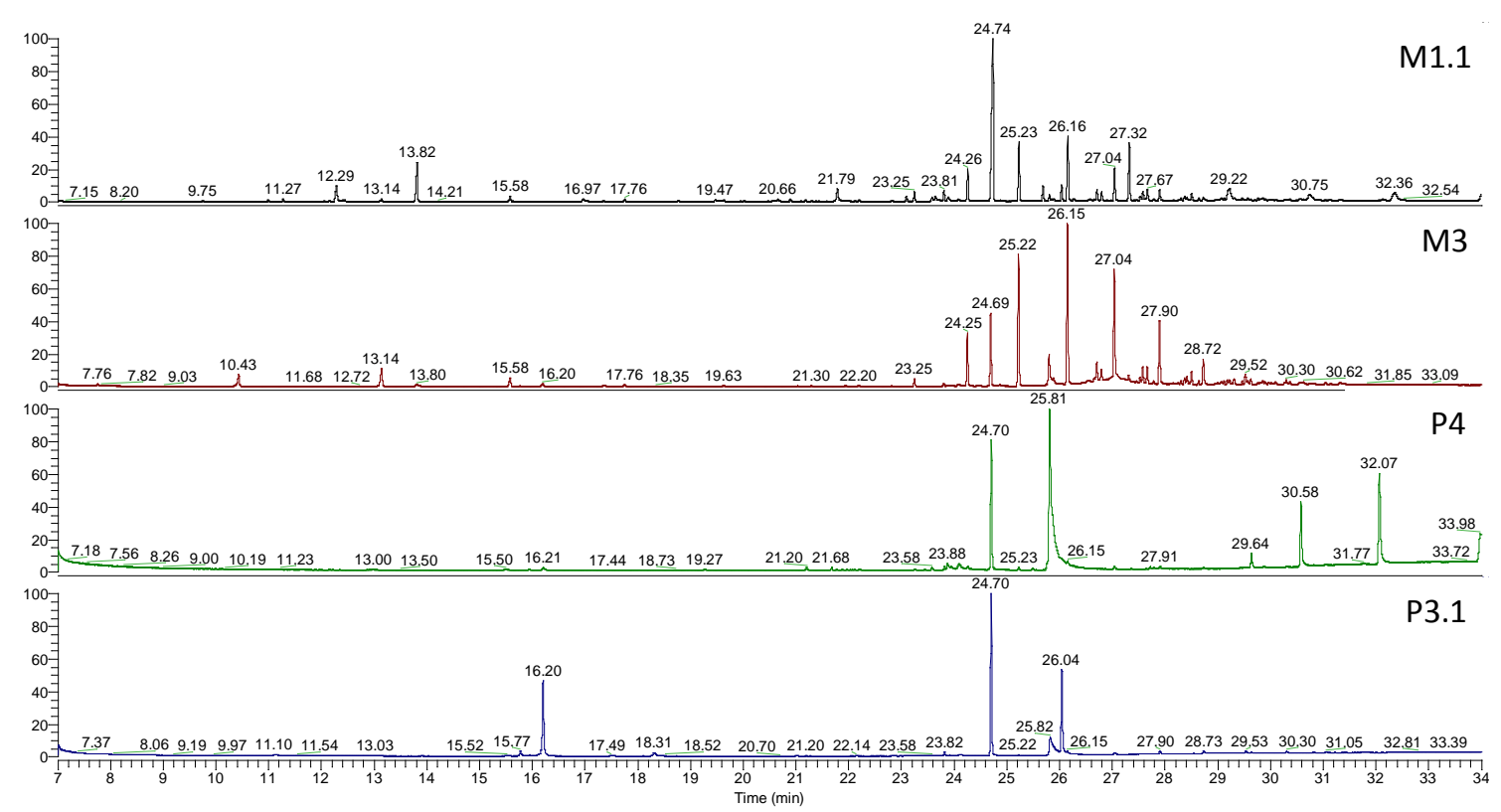

Figure 1. Mass spectrometry coupled to gas chromatography (GC-MS) chromatograms of samples M1.1, M3, P4, and P3.1.

Table 2 summarizes the compounds identified in the acetonitrile extracts, but only library matches with a direct matching factor (SI) and a reverse search matching (RSI) higher than 700 were included.

$\mathrm{N}$-alkanes between C21 and C29 were identified in most of the wrappers that were analyzed. Thus, pentacosane was found in all of samples, while, among others, tricosane, heptacosane and octacosane were found in seven of the eight samples analyzed (P1, P3.1, P3.2, P4, P5, P6 and P7). On the other hand, the sample P7 contained all of the identified alkanes except docosane. Saturated alkanes are usually present in polymers.

Rani et al. (2015) [10] reported the presence of hydrocarbons in plastic materials such as polypropylene (PP) and polyethylene (PE) and as well in polyethyl terephthalate (PET) and acrylic/styrene. They were also found in both virgin and recycled PP and in PP bottles [11,12].

Butylated hydroxytoluene (BHT) is a common antioxidant that is used as a stabilizer for polyolefins. It has also been identified in polyurethane adhesives [13,14]. Its use as an additive in the manufacture of plastic materials that are intended to come into contact with food is allowed, and has a specific migration limit (SML) of $3 \mathrm{mg} / \mathrm{kg}$ (Commission Regulation (EU) No 10/2011) [7]. Besides, it is also employed as a food additive. The antioxidant was identified in six samples (P2, P3.1, 
P3.2, P4, P5 and P6). Moreover, 2,6-Di-tert-butyl-4-methylene-2,5-cyclohexadienone, a degradation product of BHT, was detected in three samples (P3.1, P3.2 and P5). Particular attention has been paid to the degradation products since according to some studies, they could represent a risk for the consumers' health [15]. Both compounds identified are classified as class II according to Cramer rules.

Different plasticizers such as acetyl tributyl citrate, tributyl aconitate, bis(2-ethylhexyl) adipate, and phthalates were also identified in the plastic wrappers analyzed. The main function of plasticizers is to improve the flexibility and processability of polymers [16-18]. Acetyl tributyl citrate and tributyl aconitate were identified in all of the samples, while bis(2-ethylhexyl) adipate was identified in all of the samples except in samples P1 and P7. Due to its low cost, this compound is widely used, especially in polyvinyl chloride (PVC) films $[16,17,19]$. Among the phthalates, diethyl phthalate and bis(2-ethylhexyl) phthalate were detected in all of the samples except in sample P2 and P3.1, respectively. Diisobutyl phthalate was identified in the samples P1, P3.2, P4 and P5. Low molecular weight phthalates such as diethyl phthalate and diisobutyl phthalate have been used, among other applications in printing inks, adhesives, etc. On the other hand, high molecular weight phthalates such as bis(2-ethylhexyl) phthalate are mostly used in PVC [20]. Some plasticizers, including bis(2-ethylhexyl) adipate and phthalates, have been described as endocrine disruptors $[19,21]$.

Triacetin was detected only in sample P2; this substance has been reported as the main compound in plastic laminated paper [22]. Besides its use as food additive, it is allowed and has been classified as Generally Recognized As Safe (GRAS) by the Food and Drug Administration (FDA) [23].

7,9-Di-tert-butyl-1-oxaspiro(4,5)deca-6-9-diene-2,8-dione was the only identified compound classified in category III according to the Cramer rules. This substance has been described as a degradation product of the antioxidant Irganox $1010[13,24]$. Therefore, it could be considered as a non-intentionally added substance (NIAS) [4]. It was detected in all of the samples except in sample P4.

Diethyl maleate was detected in four samples (P1, P3.1, P3.2 and P.5); this compound is used to functionalize polymers such as polyolefins [25].

Other compounds that were also identified were squalene, a hydrocarbon used as plasticizer, which was detected in all of the samples, and glycerol tricaprylate, a lubricant found in samples P1, P6 and P7 $[10,26]$.

It is important to note that many of the identified compounds are not on the European Union positive list of the allowed substances to be employed in plastic materials intended to come into contact with food. 
Table 2. Compounds identified in the plastic-based candy wrappers and their class of toxicity according to Cramer rules.

\begin{tabular}{|c|c|c|c|c|c|c|c|c|c|c|c|c|c|}
\hline$t_{\mathrm{R}}(\min )$ & Compound & CAS & $m / z$ & TC & $\begin{array}{c}\text { SML } \\
\text { Use: M/A }\end{array}$ & P1 & P2 & P3.1 & P3.2 & P4 & P5 & P6 & P7 \\
\hline 11.07 & Diethyl maleate & $141-05-9$ & 99,127 & I & _- & $\mathrm{x}$ & & $\mathrm{x}$ & $\mathrm{x}$ & & $\mathrm{x}$ & & \\
\hline 13.81 & *Triacetin & $102-76-1$ & $43,103,145$ & I & - & & $\mathrm{X}$ & & & & & & \\
\hline 15.78 & 2,6-Di-tert-butyl-4-methylene-2,5-cyclohexadienone & $2607-52-5$ & $161,203,175$ & II & & & & $x$ & $\mathrm{x}$ & & $\mathrm{X}$ & & \\
\hline 16.21 & * Butylated hydroxytoluene & $128-37-0$ & 205,220 & II & $3 \mathrm{~A}$ & & $x$ & $x$ & $\mathrm{x}$ & $x$ & $\mathrm{X}$ & $\mathrm{x}$ & \\
\hline 17.35 & * Diethyl phthalate & $84-66-2$ & 149,177 & I & - & $\mathrm{x}$ & & $\mathrm{x}$ & $x$ & $x$ & $x$ & $\mathrm{x}$ & $\mathrm{x}$ \\
\hline 20.67 & * Diisobutyl phthalate & $84-69-5$ & 149,223 & I & - & $x$ & & & $x$ & $x$ & $x$ & & \\
\hline 21.19 & 7,9-Di-tert-butyl-1-oxaspiro(4,5)deca-6-9-diene-2,8-dione & $82304-66-3$ & $57,205,55,175$ & III & - & $\mathrm{x}$ & $x$ & $\mathrm{x}$ & $\mathrm{x}$ & & $x$ & $x$ & $x$ \\
\hline 23.26 & *Heneicosane & 629-94-7 & $57,71,85$ & I & - & & $x$ & & & $x$ & $x$ & $\mathrm{x}$ & $x$ \\
\hline 23.82 & Tributyl aconitate & 7568-58-3 & $112,157,139$ & I & _ & $\mathrm{X}$ & $\mathrm{X}$ & $x$ & $\mathrm{x}$ & $\mathrm{x}$ & $\mathrm{x}$ & $\mathrm{x}$ & $\mathrm{X}$ \\
\hline 24.26 & * Docosane & $629-97-0$ & $57,71,85$ & I & - & & $x$ & $\mathrm{x}$ & & $x$ & $x$ & $x$ & \\
\hline 24.71 & * Acetyl tributyl citrate & 77-90-7 & $185,259,129$ & I & $* * 60 \mathrm{~A}$ & $\mathrm{x}$ & $x$ & $\mathrm{x}$ & $x$ & $x$ & $x$ & $\mathrm{x}$ & $x$ \\
\hline 25.22 & ${ }^{*}$ Tricosane & $638-67-5$ & $57,71,85$ & I & - & $x$ & & $\mathrm{x}$ & $x$ & $x$ & $x$ & $x$ & $x$ \\
\hline 26.06 & ${ }^{*}$ Bis(2-ethylhexyl) adipate & $103-23-1$ & 129,147 & I & $* * 60 \mathrm{~A}$ & & $x$ & $\mathrm{x}$ & $x$ & $x$ & $x$ & $\mathrm{x}$ & \\
\hline 26.15 & * Tetracosane & $646-31-1$ & $57,71,85$ & I & - & $x$ & $x$ & & $X$ & $x$ & $X$ & $x$ & $x$ \\
\hline 27.04 & ${ }^{*}$ Pentacosane & $629-99-2$ & $57,71,85$ & I & - & $x$ & $x$ & $x$ & $x$ & $x$ & $x$ & $x$ & $x$ \\
\hline 27.32 & ${ }^{*}$ Bis(2-ethylhexyl) phthalate & $117-81-7$ & 149,167 & I & $* * 1,5 \mathrm{~A}$ & $x$ & $x$ & & $x$ & $x$ & $x$ & $x$ & $x$ \\
\hline 27.90 & ${ }^{*}$ Hexacosane & $630-01-3$ & $57,71,85$ & I & - & $x$ & $x$ & $x$ & $x$ & $x$ & $x$ & & $x$ \\
\hline 28.73 & ${ }^{*}$ Heptacosane & $593-49-7$ & $57,71,85$ & I & _ & $\mathrm{x}$ & & $x$ & $x$ & $x$ & $x$ & $\mathrm{x}$ & $\mathrm{x}$ \\
\hline 29.64 & * Squalene & $111-02-4$ & 69,81 & I & - & $x$ & $x$ & $x$ & $x$ & $x$ & $x$ & $x$ & $x$ \\
\hline 30.30 & ${ }^{*} \mathrm{n}$-Nonacosane & $630-03-5$ & $57,71,85$ & I & - & $x$ & & $x$ & & & $x$ & $x$ & $x$ \\
\hline 30.57 & ${ }^{*}$ Glycerol tricaprylate & $538-23-8$ & $127,57,327,201$ & I & - & $x$ & & & & & & $x$ & $x$ \\
\hline
\end{tabular}

${ }^{*}$ Confirmed with standards. A: Additive, M: Monomer. ${ }^{* *}$ The restriction applies for the sum of a group of substances. .: not included in European Union positive list. 


\subsubsection{Paper-Based Materials}

Table 3 list the 28 compounds identified in paper-based wrappers; 20 of them were confirmed with standards. Several of the compounds found such as, $N$-alkanes, phthalates, butylated hydroxytoluene, acetyl tributyl citrate, tributyl aconitate, bis(2-ethylhexyl) adipate, and so on were also identified in the plastic-based samples.

Regarding $N$-alkanes in these paper-based samples, we also identified octadecane, nonadecane, and eicosane with 18, 19 and 20 carbon atoms. Octadecane was detected in samples M1.1, M1.2, M3, M4 and M5; in the case of nonadecane and eicosane, they were found in all samples except in samples PA1 and PA2 nonadecane and sample PA2 eicosane. As it has been reported elsewhere, $\mathrm{N}$-alkanes may have their origin in the paraffin wax, which is commonly used as coating in paper-based materials for food packaging applications [27].

With respect to phthalates, bis(2-ethylhexyl) phthalate was identified in all of the samples, whereas diethyl phthalate and diisobutyl phthalate were detected in all of the samples except in samples PA2 and M4, respectively. Benzyl butyl phthalate was only identified in three samples M1.1, M1.2, and M5, and was not found in plastic-based samples. Other plasticizers such as acetyl tributyl citrate was detected in all of the samples except in M1.2 or bis(2-ethylhexyl) adipate, which was identified in four samples: M1.1, M1.2, M3 and PA2.

Triacetin was identified in seven of the nine samples analyzed (M1.1, M1.2, M2.1, M2.2, M3, M4, and M5); however, in plastic-based materials, it was only detected in one sample.

Other compounds identified were heptadecylcyclohexane, octadecanoic acid, and palmitic acid, which have been reported as a lubricant, a slip agent, and a slip agent degradant, respectively [28].

7,9-Di-tert-butyl-1-oxaspiro(4,5)deca-6-9-diene-2,8-dione was identified in M1.1, M1.2, M2.1, M2.2, M3, M4 and M5; as it has been commented on above, it is classified in class III according to Cramer rules. 
Table 3. Compounds identified in the paper-based candy wrappers and their class of toxicity according to Cramer rules.

\begin{tabular}{|c|c|c|c|c|c|c|c|c|c|c|c|c|c|}
\hline$t_{\mathrm{R}}(\min )$ & Compound & CAS & $m / z$ & TC & M1.1 & M1.2 & M2.1 & M2.2 & M3 & M4 & M5 & PA.1 & PA.2 \\
\hline 13.81 & ${ }^{*}$ Triacetin & $102-76-1$ & $43,103,145$ & I & $x$ & $\mathrm{x}$ & $\mathrm{x}$ & $\mathrm{x}$ & $x$ & $\mathrm{x}$ & $x$ & & \\
\hline 16.21 & * Butylated hydroxytoluene & $128-37-0$ & 205,220 & II & & & $x$ & $x$ & $x$ & $x$ & $x$ & & \\
\hline 17.35 & * Diethyl phthalate & $84-66-2$ & 149,177 & I & $X$ & $\mathrm{X}$ & $x$ & $\mathrm{X}$ & $X$ & $X$ & $x$ & $x$ & \\
\hline 19.95 & * Octadecane & $593-45-3$ & $57,71,85$ & I & $x$ & $\mathrm{x}$ & & & $x$ & $x$ & $x$ & & \\
\hline 20.66 & ${ }^{*}$ Diisobutyl phthalate & $84-69-5$ & 149,223 & I & $x$ & $x$ & $x$ & $x$ & $x$ & & $x$ & $x$ & $x$ \\
\hline 21.11 & ${ }^{*}$ Nonadecane & $629-92-5$ & $57,71,85$ & I & $x$ & $x$ & $x$ & $x$ & $x$ & $\mathrm{X}$ & $x$ & & \\
\hline 21.18 & 7,9-Di-tert-butyl-1-oxaspiro(4,5)deca-6-9-diene-2,8-dione & $82304-66-3$ & $57,205,55,175$ & III & $\mathrm{X}$ & $\mathrm{x}$ & $\mathrm{x}$ & $\mathrm{X}$ & $\mathrm{X}$ & $\mathrm{X}$ & $\mathrm{X}$ & & \\
\hline 21.80 & Palmitic acid & $57-10-3$ & $73,43,129$ & I & $\mathrm{X}$ & $\mathrm{X}$ & $\mathrm{X}$ & $\mathrm{x}$ & & $\mathrm{X}$ & $\mathrm{X}$ & $\mathrm{X}$ & \\
\hline 22.20 & *Eicosane & $112-95-8$ & $57,71,85$ & I & $x$ & $\mathrm{X}$ & $\mathrm{x}$ & $\mathrm{x}$ & $\mathrm{X}$ & $x$ & $\mathrm{X}$ & $\mathrm{x}$ & \\
\hline 23.26 & * Heneicosane & $629-94-7$ & $57,71,85$ & I & $\mathrm{X}$ & $\mathrm{x}$ & $\mathrm{X}$ & $\mathrm{x}$ & $\mathrm{X}$ & $\mathrm{X}$ & $\mathrm{X}$ & & \\
\hline 23.66 & Oleic acid & $112-80-1$ & $55,97,69,83$ & I & $x$ & $x$ & $x$ & $x$ & & $x$ & $x$ & & \\
\hline 23.81 & Tributyl aconitate & 7568-58-3 & $112,157,139$ & I & $x$ & $\mathrm{x}$ & $x$ & $x$ & $x$ & $x$ & $x$ & & \\
\hline 23.88 & Octadecanoic acid (STEARIC ACID) & 57-11-4 & $43,73,60,129$ & I & $\mathrm{X}$ & $\mathrm{x}$ & $\mathrm{X}$ & $\mathrm{X}$ & & $\mathrm{X}$ & $\mathrm{X}$ & & \\
\hline 24.25 & ${ }^{*}$ Docosane & $629-97-0$ & $57,71,85$ & I & $x$ & & $\mathrm{x}$ & $x$ & $\mathrm{X}$ & $\mathrm{X}$ & $x$ & & \\
\hline 24.71 & * Acetyl tributyl citrate & 77-90-7 & $185,259,129$ & I & $x$ & & $\mathrm{x}$ & $x$ & $x$ & $x$ & $x$ & $x$ & $x$ \\
\hline 25.23 & * Tricosane & $638-67-5$ & $57,71,85$ & I & $x$ & $\mathrm{X}$ & $x$ & $x$ & $x$ & $x$ & $x$ & $x$ & $x$ \\
\hline 25.69 & * Benzyl butyl phthalate & 85-68-7 & $91,149,206$ & I & $x$ & $x$ & & & & & $x$ & & \\
\hline 26.05 & ${ }^{*}$ Bis(2-ethylhexyl) adipate & $103-23-1$ & 129,147 & I & $\mathrm{X}$ & $\mathrm{x}$ & & & $\mathrm{x}$ & & & & $x$ \\
\hline 26.16 & * Tetracosane & $646-31-1$ & $57,71,85$ & I & $x$ & $\mathrm{x}$ & $\mathrm{x}$ & $\mathrm{x}$ & $\mathrm{X}$ & $x$ & $x$ & $\mathrm{X}$ & $x$ \\
\hline 27.05 & ${ }^{*}$ Pentacosane & $629-99-2$ & $57,71,85$ & I & & $x$ & $x$ & $x$ & $x$ & & $\mathrm{x}$ & & $\mathrm{x}$ \\
\hline 27.32 & ${ }^{*}$ Bis(2-ethylhexyl) phthalate & $117-81-7$ & 149,167 & I & $\mathrm{X}$ & $x$ & $x$ & $x$ & $x$ & $\mathrm{X}$ & $x$ & $\mathrm{X}$ & $x$ \\
\hline 27.91 & ${ }^{*}$ Hexacosane & $630-01-3$ & $57,71,85$ & I & $x$ & $x$ & $x$ & $x$ & $x$ & $x$ & $x$ & $x$ & \\
\hline 28.74 & ${ }^{*}$ Heptacosane & $593-49-7$ & $57,71,85$ & I & $\mathrm{X}$ & $\mathrm{X}$ & $\mathrm{X}$ & $\mathrm{X}$ & $\mathrm{X}$ & $\mathrm{X}$ & $\mathrm{X}$ & & \\
\hline 29.12 & 2,4-dimethylicosane & 75163-98-3 & $85,84,43,57$ & I & $x$ & $x$ & & & $x$ & $x$ & $x$ & & \\
\hline 29.57 & Heptadecylcyclohexane & 19781-73-8 & $57,82,83$ & I & $\mathrm{X}$ & $\mathrm{x}$ & $\mathrm{X}$ & & $\mathrm{X}$ & $\mathrm{X}$ & $\mathrm{X}$ & & \\
\hline 29.64 & $*$ Squalene & $111-02-4$ & 69,81 & I & $x$ & $x$ & $x$ & $\mathrm{x}$ & $x$ & & $x$ & $\mathrm{X}$ & $\mathrm{x}$ \\
\hline 30.57 & * Glycerol tricaprylate & $538-23-8$ & $127,57,327,201$ & I & & & & & & & & $x$ & $x$ \\
\hline 32.36 & 1,2-Didodecanoylglycerol & $17598-94-6$ & 183, 257 & I & $\mathrm{X}$ & $x$ & & & & $\mathrm{X}$ & $\mathrm{X}$ & & \\
\hline
\end{tabular}

* Confirmed with standards. 


\subsection{Targeted Analysis}

With the aim to identify photoinitiators in the packaging samples, a target analysis was carried out. Only one of the photoinitiators evaluated was detected in the samples analyzed. 2-Hydroxybenzophenone was found in five samples: PA1, PA2, P2, P6 and P7.

In brief, here we present a simple methodology based on a GC-MS analysis to identify potential volatile migrants in both intentionally and non-intentionally added substances in food packaging materials. The proposed method could be useful as a screening approach in control laboratories for compliance with legislation. Our results showed that many compounds identified in plastic-based materials are not in the positive list of the Regulation 10/2011 [7].

Author Contributions: A.R.-B.D.Q., R.S. and J.L.H. conceived and designed the experiments, analyzed the data and wrote the paper; S.G.G. performed the experiments.

Funding: This research was funded by the "Ministerio de Economía y Competitividad", "Fondo Europeo de Desarrollo Regional (FEDER) and by "Agencia Estatal de Investigación" Ref.No. AGL2015-69609-P "MIGRAEXPO". (MINECO/FEDER,UE).

Conflicts of Interest: The authors declare no conflict of interest.

\section{References}

1. Lau, O.W.; Wong, S.K. Contamination in food from packaging material. J. Chromatogr. A 2000, 882, 255-270. [CrossRef]

2. Castle, L. Chemical migration into food: an overview. In Chemical Migration and Food Contact Materials, 1st ed.; Barnes, K.A., Sinclair, C.R., Eds.; CRC Press: Boca Raton, FL, USA, 2007; pp. 1-13. ISBN 978-0-8493-9130-9.

3. Sanchis, Y.; Yusà, V.; Coscollà, C. Analytical strategies for organic food packaging contaminants. J. Chromatogr. A 2017, 1490, 22-46. [CrossRef] [PubMed]

4. Nerin, C.; Alfaro, P.; Aznar, M.; Domeño, C. The challenge of identifying non-intentionally added substances from food packaging materials: A review. Anal. Chim. Acta 2013, 775, 14-24. [CrossRef] [PubMed]

5. Koster, S.; Bani-Estivals, M.H.; Bonuomo, M.; Bradley, E.; Chagnon, M.C.; Garcia, M.L.; Godts, F.; Gude, T.; Helling, R.; Paseiro-Losada, P.; et al. Guidance on best practices on the risk assessment of non intentionally added substances (NIAS) in food contact materials and articles. In Proceedings of the International Life Sciences Institute Europe, Brussels, Belgium, 16 July 2015.

6. Regulation (EC) No. 1935/2004, on Materials and Articles Intended to Come into Contact with Food and Repealing Directives 80/590/EEC and 89/109/EEC. Available online: http://data.europa.eu/eli/reg/2004/ 1935/ oj (accessed on 27 October 2004).

7. Commission Regulation (EU) No. 10/2011, on Plastic Materials and Articles intended to Come into Contact with Food. Available online: http:/ / data.europa.eu/eli/reg/2011/10/oj (accessed on 14 January 2011).

8. Toxtree v2.6.13. Available online: http://toxtree.sourceforge.net/download.html (accessed on 7 September 2017).

9. Cramer, G.M.; Ford, R.A.; Hall, R.L. Estimation of toxic hazard-decision tree approach. Food Cosmet. Toxicol. 1978, 716, 255-276. [CrossRef]

10. Rani, M.; Shim, W.J.; Han, G.M.; Jang, M.; Al-Odaini, N.A.; Song, Y.K.; Hong, S.H. Qualitative analysis of additives in plastic marine debris and its new products. Arch. Environ. Contam. Toxicol. 2015, 69, 352-366. [CrossRef] [PubMed]

11. Camacho, W.; Karlsson, S. Quality-determination of recycled plastic packaging waste by identification of contaminants by GC-MS after microwave assisted extraction (MAE). Polym. Degrad. Stab. 2001, 71, 123-134. [CrossRef]

12. Onghena, M.; van Hoeck, E.; Vervliet, P.; Scippo, M.L.; Simon, C.; van Loco, J.; Covaci, A. Development and application of a non-targeted extraction method for the analysis of migrating compounds from plastic baby bottles by GC-MS. Food Addit. Contam. Part A 2014, 31, 2090-2102. [CrossRef] [PubMed]

13. Félix, J.S.; Isella, F.; Bosetti, O.; Nerín, C. Analytical tools for identification of non-intentionally added substances (NIAS) coming from polyurethane adhesives in multilayer packaging materials and their migration into food simulants. Anal. Bioanal. Chem. 2012, 403, 2869-2882. [CrossRef] [PubMed] 
14. Bach, C.; Dauchy, X.; Chagnon, M.C.; Etienne, S. Chemical compounds and toxicological assessments of drinking water stored in polyethylene terephthalate (PET) bottles: A source of controversy reviewed. Water Res. 2012, 46, 571-583. [CrossRef] [PubMed]

15. Nieva-Echevarrí1a, B.; Manzanos, M.J.; Goicoechea, E.; Guillén, M.D. 2,6-Di-tert-butyl-hydroxytoluene and its metabolites in foods. Compr. Rev. Food Sci. Food Saf. 2015, 14, 67-80. [CrossRef]

16. Lajqi-Makolli, V.; Kerolli-Mustafa, M.; Malollari, I.; Lajqi, J. Migration of di-(2-ethylhexyl)adipate (DEHA) and acetyl tributyl citrate (ATBC) plasticizers from PVC film into the food stimulant of isooctane. Mater. Sci. Eng. Technol. 2015, 46, 16-23. [CrossRef]

17. Bazilio, F.S.; Bomfim, M.V.J.; Almeida, R.J.; Abrantes, S.M.P. Intralaboratory validation of an analytical method for determining the migration of bis(2-ethylhexyl) adipate from packaging to fat foods. Accred. Qual. Assur. 2014, 19, 195-204. [CrossRef]

18. Dupáková, Z.; Dobiáš, J.; Votavová, L.; Klaudisová, K.; Voldrich, M. Occurrence of extractable ink residuals in packaging materials used in the Czech Republic. Food Addit. Contam. Part A 2010, 27, 97-106. [CrossRef] [PubMed]

19. Fasano, E.; Bono-Blay, F.; Cirillo, T.; Montuori, P.; Lacorte, S. Migration of phthalates, alkylphenols, bisphenol A and di(2-ethylhexyl)adipate from food packaging. Food Control 2012, 27, 132-138. [CrossRef]

20. Sakhi, A.K.; Lillegaard, I.T.L.; Voorspoels, S.; Carlsen, M.H.; Løkend, E.B.; Brantsæter, A.L.; Haugen, M.; Meltzer, H.M.; Thomsen, C. Concentrations of phthalates and bisphenol A in Norwegian foods and beverages and estimated dietary exposure in adults. Environ. Int. 2014, 73, 259-269. [CrossRef] [PubMed]

21. Fierens, T.; Standaert, A.; Cornelis, C.; Sioen, I.; De Henauw, S.; Willems, H.; Bellemans, M.; De Maeyer, M.; Van Holderbeke, M. A semi-probabilistic modelling approach for the estimation of dietary exposure to phthalates in the Belgian adult population. Environ. Int. 2014, 73, 117-127. [CrossRef] [PubMed]

22. Guazzotti, V.; Giussani, B.; Piergiovanni, L.; Limbo, S. Screening for chemicals in paper and board packaging for food use: Chemometric approach and estimation of migration. Packag. Technol. Sci. 2015, 28, 385-395. [CrossRef]

23. Panseri, S.; Chiesa, L.M.; Zecconi, A.; Soncini, G.; De Noni, I. Determination of volatile organic compounds (VOCs) from Wrapping films and wrapped pdo italian cheeses by using HS-SPME and GC/MS. Molecules 2014, 19, 8707-8724. [CrossRef] [PubMed]

24. Skjevrak, I.; Brede, C.; Steffensen, I.L.; Mikalsen, A.; Alexander, J.; Fjeldal, P.; Herikstad, H. Non-targeted multi-component analytical surveillance of plastic food contact materials: Identification of substances not included in EU positive lists and their risk assessment. Food Addit. Contam. 2005, 22, 1012-1022. [CrossRef] [PubMed]

25. Albano, C.; Perera, R.; Sánchez, Y.; Karam, A.; Silva, P. Comparative study of different initiation methods in the functionalization of low-density polyethylene with diethyl maleate: Gamma radiation and ultrasound. Nucl. Instrum. Meth. B 2007, 265, 208-212. [CrossRef]

26. Ruellan, A.; Guinault, A.; Sollogoub, C.; Ducruet, V.; Domenek, S. Solubility factors as screening tools of biodegradable toughening agents of polylactide. J. Appl. Polym. Sci. 2015, 132, 42476. [CrossRef]

27. Pezo, D.; Wrona, M.; Rodriguez-Lafuente, A.; Nerin, C. A sulphuric acid-impregnated silica gel clean-up procedure for the determination of n-alkanes migration from paraffin based paper packaging into cheddar cheese. Food Chem. 2012, 134, 405-411. [CrossRef]

28. Lago, M.A.; Ackerman, L.K. Identification of print-related contaminants in food packaging. Food Addit. Contam. Part A 2016, 33, 518-529. [CrossRef] [PubMed]

(C) 2018 by the authors. Licensee MDPI, Basel, Switzerland. This article is an open access article distributed under the terms and conditions of the Creative Commons Attribution (CC BY) license (http:/ / creativecommons.org/licenses/by/4.0/). 